REVESCO. Revista de Estudios Cooperativos

ISSN: $1885-8031$

http://dx.doi.org/10.5209/REVE.58134

\title{
Modelos influyentes en las cooperativas de ahorro y crédito en Colombia
}

\author{
Luz Patricia Pardo Martínez ${ }^{1}$ y María Victoria Huertas de Mora ${ }^{2}$
}

Recibido: 10 de junio de 2016 / Aceptado: 17 de septiembre de 2017

Resumen. El estudio sobre las "modelos influyentes de las cooperativas de ahorro y crédito en Colombia", permite determinar las prácticas que han asegurado la viabilidad y permanencia de dichas organizaciones, porque han facilitado el desarrollo socio económico de sus miembros, así como el mejor estar en las comunidades donde actúan. Igualmente, permite identificar el o los modelos referentes internacionales para estas organizaciones y su grado de influencia.

La metodología empleada fue el método comparativo con estudio de caso, el cual brindo la posibilidad de análisis y reflexión de las prácticas de las organizaciones objeto de estudio; abordando la comparación de los modelos influyentes, tipificados a nivel tanto nacional como internacional y que en alguna época fueron referentes para las organizaciones cooperativas en Colombia, en sus prácticas de ahorro y crédito. Plantea al lector los procesos, los desarrollos y las prácticas que se mostraron determinantes para la estabilidad de las organizaciones cooperativas de ahorro y crédito en cada uno de los momentos históricos, demarcando su alcance.

Palabras clave: Modelos influyentes; Cooperativas ahorro y crédito; Desarrollo; Social.

Claves Econlit: P130; G10; G21.

\section{[en] Influential models in the cooperatives of savings and credits in Colombia}

Abstract. This study on the "influential models of cooperatives in Colombia", aims to identify the practices that have the Insured the viability and permanence of such organizations, because have facilitated the development of their Social and Economic as well that of the communities where they operate Members. Identify models or International references have been concerning paragraph these organizations and their degree of influence.

The methodology used was the comparative case study method, which provided the opportunity for analysis and reflection of the organizations under study; addressing comparing the influential models between established at national and international level, which at one time were related to cooperative organizations in Colombia, in their practices of savings and credit, raises the reader processes, developments and practices they were decisive for the stability of cooperative savings and credit organizations in each of the historical moments, demarcating their scope marking reach.

Keywords: Influential models; Cooperatives credit union; Social development.

1 Universidad Cooperativa de Colombia

Dirección de correo electrónico: 1uz.pardo@campusucc.edu.co

2 Universidad Cooperativa de Colombia

Dirección de correo electrónico: marivihuertas@yahoo.com 
Sumario. 1. Introducción. 2. La doctrina cooperativa. 3. Los modelos - referentes internacionales. 4. El cómo del modelo nacional en Colombia. 5. Conclusiones. 6. Referencias bibliográficas.

Cómo citar: Pardo Martínez, L.P. y Huertas de Mora, M.V. (2017) Modelos influyentes en las cooperativas de ahorro y crédito en Colombia. REVESCO. Revista de Estudios Cooperativos, № 125 , pp. 109-133. DOI: 10.5209/REVE.58134.

\section{Introducción}

Más allá de las dificultades que supuso la crisis de la economía colombiana de los años 90 del siglo XX y que afectó fundamentalmente a las organizaciones cooperativas de ahorro y crédito, se identifican tres temas importantes que son del interés investigativo para superar el nivel que, a veces especulativamente, caracteriza su tratamiento.

En primer lugar, se muestra el interés de los investigadores por rescatar el fundamento central de la organización cooperativa en sus conceptos básicos en cuanto a que un miembro es: asociado, dueño, usuario y autogestor organizacional; que permiten entender estas relaciones, a veces polémicas y antagónicas, de la organización cooperativa, en nuestro caso de estudio, la de ahorro y crédito. Refiere este tema a la doctrina cooperativa.

En segundo lugar, como un aporte al análisis y reflexión del mismo grupo estudiado y desde una mirada de los modelos influyentes, se aborda la pregunta ¿Cuál ha sido la incidencia de referentes internacionales en las diversas prácticas de ahorro y crédito en las cooperativas de Colombia?.

En tercer lugar, tres momentos diferentes pero complementarios son del interés de los investigadores y hacen referencia a:

- Una comparación entre los modelos internacionales influyentes en el cooperativismo de Colombia y las prácticas de ahorro y crédito de las organizaciones cooperativas colombianas, identificando semejanzas y diferencias.

- Las Prácticas de ahorro y crédito más representativas como incidentes en el desarrollo y estabilidad de las organizaciones cooperativas colombianas.

- $\quad$ Las acciones y prácticas priorizadas por las organizaciones cooperativas de ahorro y crédito, seleccionadas como sujetos de estudio, que se observan orientadas a contribuir eficazmente en el desarrollo de sus asociados, sus intenciones de incidir en las comunidades donde actúan y la claridad para proponerse como un sistema sólido y solvente en su actividad y como forma para redistribución de la riqueza.

Las preguntas que orientan estas inquietudes investigativas, en cuanto al desarrollo social y doctrinal de las cooperativas son: ¿Cuál ha sido la incidencia de las diversas prácticas de ahorro y crédito en las cooperativas de Colombia? Y ¿Cuales han sido los factores críticos que han tenido efecto en su doctrina y eventualmente han hecho modificar sus prácticas como cooperativas del ahorro y el crédito? 
El artículo que se presenta a continuación es producto de una investigación del grupo ARTE SOLIDARIO sobre las prácticas de las cooperativas de ahorro y crédito y los modelos influyentes en Colombia.

\subsection{Justificación}

Cualquier movimiento socioeconómico de importancia está respaldado por un modelo definido, que a su vez se asienta sobre principios doctrinales y valores construidos en un proceso de interacciones sociales que lo ponen a prueba, y en muchos casos, lo moldean y lo consolidan. El movimiento cooperativo no es una excepción; de hecho, lo que actualmente enarbola el sistema cooperativo (base del sistema solidario en Colombia) es justamente lo que más identidad y orgullo le ha prodigado históricamente y le ha permitido sostenerse en medio de avatares y crisis que los otros sistemas con los que cohabita le generan.

Como avance en el análisis y reflexión de la evolución de los modelos administrativos que se van perfilando y los alcances de lo doctrinal, el trabajo responde a enriquecer el fundamento y rol de las cooperativas en Colombia, tanto en su dimensión académica como en aquella de institución auxiliar del cooperativismo, la economía social y solidaria, porque estaría aportando en la construcción analítica y teórica al sector.

Diversos son los problemas que resuelve la investigación entre los que se cuentan:

Diversidad de imaginarios de lo que es "la cooperativa" y de las diferentes figuras jurídicas reconocidas en Colombia.

Las opciones y oportunidades que las cooperativas brindan para el desarrollo humano.

Apropiación de los postulados cooperativos y de solidaridad en discursos desarticulados y ausentes de rigor conceptual.

Los hallazgos y resultados del trabajo propuesto benefician directamente a las cooperativas de ahorro y crédito. Además puede brindar orientación a las demás organizaciones solidarias, que al identificar sus procesos y desarrollos organizacionales; podrán reconocer el sustancial cambio de rumbo que se viene presentado en los distintos tipos de cooperativas junto con sus implicaciones.

\subsection{Objetivo general}

Identificar Los modelos que han influido históricamente en el desarrollo de las cooperativas de ahorro y crédito en Colombia y su incidencia en la gestión administrativa del sector cooperativo.

\subsection{Objetivos específicos}

Identificar las formas de aplicación doctrinal reflejada en la gestión administrativa, en sendos casos de estudio, cooperativas de ahorro y crédito.

Comparar los procesos, estructuras y métodos organizativos de las entidades estudiadas, estableciendo las diferencias y semejanzas con el marco autoreferencial propuesto. 
Analizar las dinámicas administrativas y las transformaciones que históricamente han venido dándose en Colombia desde la perspectiva doctrinal cooperativa.

\subsection{Metodología}

El método comparativo encierra el propósito de su acción en la interpretación del quehacer humano; en este particular se refiriere a la esfera cooperativa con el objeto de comprender la incidencia de los modelos en la gestión administrativa del sector en Colombia.

Para responder a esta crucial pregunta, la primera categoría de análisis abordada, se trabaja mediante rastreo documental. Las siguientes categorías de análisis y reflexión se elaboran a partir del método comparativo, orientado a identificar los factores o variables decisivos, que como lo define Rosselló "el método como el conjunto homogéneo de acontecimientos, cuya importancia pedagógica, medida en función del tiempo, se estanca, crece o disminuye" (Rosselló 1974:23).

Hoy, extrapolado a nuestra situación de análisis, encierran la esencia de los procesos humanos y otros secundarios que se van descubriendo a medida que avanza la investigación; y que aplicados al presente trabajo hacen referencia a:

El sujeto de comparación: refiere a los modelos organizacionales de las entidades solidarias del subsector financiero y de ahorro y crédito.

El área de comparación: siendo las mismas organizaciones en su caracterización y las regiones de influencia.

El carácter de comparación: que se hace clara por explicativa y por comparativa aplicada a semejanzas y diferencias.

Para por último el sentido de la comparación: identificando la dinámica enfocada a transformaciones.

El estudio de caso complemento el método comparativo, su interés se orientó a saber por qué el objeto es tal como está. Este conocimiento ayudó a resumir todo lo que es sabido acerca las prácticas de ahorro y crédito de las organizaciones cooperativas, ayuda a verlo en su contexto y en una perspectiva histórica, desde diversos factores tales como: los elementos heredados, las experiencias, lo que los dirigentes cooperativos han aprendido. En concordancia con el planteamiento anterior, se adopta igualmente los procedimientos seguidos por Ingrid (Muller de Ceballos, 1992:10) quién plantea en sus trabajos el detalle en la aplicación de la metodología comparativa.

El método, es el comparativo, tanto histórico como de concesiones ideológicas y de situaciones sociales y políticas, que son por su naturaleza interpolares las primeras y temporales las segundas.

En cuanto a la comparación histórica es claro que se refiere a las épocas, desde una mirada retrospectiva. Por método comparativo se entiende literalmente el de la comparación de dos o más entes (hechos, personas, normas) entendiéndolos y contraponiéndolos para determinar, fenomenológicamente, esto es, por descripción comparativa de sus modos de ser, la situación humana que subyace en el fondo, esto es, la que le sirve de fundamento, teniendo en cuenta: los elementos heredados, las experiencias, lo que los dirigentes cooperativos han aprendido. 
Como complemento necesario que brinda la oportunidad de triangulación en la validación de los hechos registrados y datos recogidos, se apela a estudios de caso, seleccionados de entre muchos adelantados, aquellos que tipifican las diferentes caracterizaciones en las organizaciones estudiadas.

\section{La doctrina cooperativa}

Esta primera categoría de análisis aborda de manera muy resumida el origen y doctrina en cuanto a la forma organización cooperativa, siendo ella identificada fundamentalmente como una forma social con acciones y actividades organizacionales, desde una perspectiva concreta frente a la Justicia.

"Es una fórmula que permite al ser humano poder desarrollar su proyecto no solo de trabajo sino el vital, en cooperación con otras personas." (Aldecoa, 2009, $\mathrm{p}: 25)$

Muy pertinente es citar a Marco Antonio Mansilla, quien en su obra escrita como aporte a la celebración de los 40 años de CORFINCORA nos dice:

"La cooperativa es una empresa de democracia económica que presenta unos rasgos en la propiedad, el trabajo, la acumulación, la gestión y el reparto diferente, no capitalista, de la riqueza" (Mansilla, 2002, p: 159).

La categoría, a los efectos del presente trabajo, da por sentadas las especificidades de su carácter en lo asociativo y de la calidad y finalidad de medio, que se asigna al capital en la propuesta cooperativa. Igualmente, no redunda en lo correspondiente a su forma jurídica que la hace ser de una parte organización social y a la vez empresa.

Se aborda el tema desde otros tres grandes conceptos que conforman paradigmas de tendencia y que permiten estructurar formas cooperativas, correspondan o no, a figuras jurídicas específicamente identificadas como tales, por las leyes y procesos de reconocimiento en fiscalidad. Ellos son:

1. Un primer paradigma, enuncia que la cooperativa se configura para la solución de aquellas necesidades muy apremiantes de los miembros del colectivo en su carácter de consumidores o lo que se conoce como productores y auto consumidores -pro-sumidores-, y se puede identificar como "Soberanía del Consumidor". Son esencialmente cooperativas conformadas por consumidores y en consecuencia esa será la línea que sigan las decisiones sobre bienes y servicios a ofrecer a sus asociados.

Este paradigma pretende organizar el consumo y a los consumidores. Las estrategias para lograrlo se resumen en lograr coordinar volúmenes significativos de demanda, que permitan a la organización eliminar intermediarios comerciales en busca de apropiar, en forma asociativa, el valor generado a lo largo de la cadena de intercambios - intermediación- vía costos marginales, precios mejorados y oportunidades de suministro. De otra parte y además, busca eliminar la usura en la financiación de las operaciones, razón que justifica el porqué desde sus inicios, la cooperativa propone ventas al contado.

2. Un segundo paradigma y tendencia refiere a estrategias aplicadas. Esta tendencia propone construir un "sistema autónomo", compuesto por núcleos locales de organizaciones cooperativas; especializadas en centros urbanos, barrios, 
zonas o por actividades específicas; y en las áreas rurales se proponen cooperativas multiactivas o integrales que atiendan con suministro de bienes, organicen producción, comercialización u otros servicios, al tenor de las necesidades de las poblaciones, con vista a desarrollo en región. Al respecto de esto último, los entonces líderes cooperativos reconocidos como autores y oráculos del sector proponen:

"Se recomienda la fundación de cooperativas de funciones múltiples, dado el éxito obtenido en varios países latinoamericanos, especialmente Colombia y teniendo en cuenta la escasez general de recursos financieros y técnicos, señalando especialmente para cada clase de instituciones los servicios de crédito, producción y consumo, habitacionales y servicios especiales." (Jaramillo G. Francisco de P., Serrano Uribe Rymel y Uribe García Carlos (2005:156 p).

3. Un tercer paradigma, enuncia a la cooperativa como medio para la apropiación de los puntos de valor en el circuito o cadena de valor económico, según se trate de una actividad o se extienda a una industria. La propuesta se basa en retener, para el conjunto y en equidad, el beneficio empresarial agregado en desarrollo de aquellas actividades económicas que, según su objeto social, han sido asumidas en cada una de las cooperativas.

Esta propuesta, aunque parece similar paradigma al que se pregona en la propuesta de cooperativa multiactiva, la diferencia está en que cada actividad o proceso cooperativizado, es una organización con responsabilidades concretas frente a sus asociados y frente a la cadena de valor con la cual se identifica y que, sin perder su autonomía e identidad como tal, se compromete en alianzas, muchas veces tácitas.

Los tres presupuestos descritos, conforman un esquema bastante complejo de "Justicia Conmutativa" vía precios-costos y "justicia distributiva en equidad" que se traduce en mejores ingresos para los asociados y están expresados en retorno de excedentes a asociados o se da mediante formas de costos y precios por retorno, aseguramiento con fondos y reservas que garanticen cada vez mejores niveles de vida para los asociados y sus familias, a través de beneficios colectivos de ayuda mutua; o, como muchas veces se da, mediante la confluencia de todas las anteriores.

"Modelo de desarrollo humano, con responsabilidad en lo local, comunitario y social". Este paradigma resulta de la coyuntura de globalización que se vive en el mundo y que se da como una propuesta de "Sistema Integrado" en lo local con lo regional e internacional". (Informe; 2005:12)

La dimensión macro social y económica se propone como una Integración vertical y horizontal. Vertical en lo interno u organizacional y horizontal en el sistema de cadena de valor que se propone. El esquema de funcionamiento permite la apropiación de los valores generados por la macro injerencia, por los desarrollos tecnológicos logrados, aprehendidos y apropiados en conjunto y, por la presencia o no, en mercados ampliados, los cuales a veces son benéficos y a veces perjudiciales.

El paradigma doctrinal involucra complejizar la Justicia conmutativa vía una real participación en macro decisiones y apropiación del manejo colectivo de costos marginales, de tecnología e innovaciones en cadena; todo ello, sin descuidar lo microeconómico de pertinencia local. 
La Justicia Distributiva a su vez, se da por apropiación individual y colectiva de los beneficios, no solo cooperativos habidos en su propia gestión, sino también, de aquellos de gestión integrada al intervenir en mercados ampliados. Que por la sinergia que se desata entre asociados-familias-sociedad, tiene efectos de extensión a la comunidad y a la sociedad.

"La realidad pone en evidencia que, en el ámbito internacional, los principales grupos financieros están dando cada vez un mayor protagonismo a las políticas de responsabilidad social y medioambiental y que éstas son también cada vez más apreciadas por empleados, clientes, inversores y la sociedad en general (Lozano et al., 2005). Y detrás de estas políticas, existe una idea general de que las actuaciones socialmente responsables de las Cajas de Ahorros, no sólo son buenas en sí mismas, sino que se trata de una inversión estratégica que beneficia a las instituciones" (Segui 2012:159)

En esta categorización de macro tendencias subyacen conceptos fundamentales como son:

Una conciencia de grupo entre las personas, un sentido de fraternidad y solidaridad, una búsqueda de la justicia en la práctica social y empresarial que aplica un enfoque más profundo de cooperación - aquella de la cooperación cooperativa- reconocer al acto cooperativo como diferente al acto comercial. Cogestión cooperada, la Cooperativa y el beneficio, en este sentido se puede asumir;

La cooperativa, como forma organización actuante en una economía, sea ésta de mercado o estatal, tiene y deriva valor que no deviene tanto de su doctrina por sí misma, en tanto como cualquier empresa, comparte la urgencia de brindar solución a las necesidades de amplios grupos sociales; siendo la diferencia frente a ellas, su método y forma de hacer empresarial.

Lucro: es el equivalente a búsqueda de maximización de utilidades con adicional apropiación de beneficios empresariales para el inversionista. No lucro: es aquella intencionalidad de no lucrarse del capital invertido, que a su vez genera el concepto de excedentes y beneficios, los que son apropiados para y por el colectivo. En nuestro caso, son los excedentes y beneficios derivados de actos cooperativos y de actividades cooperativas- que la cooperativa adelanta con sus asociados y, a través de ellos y sus familias, con la comunidad.

"Un nuevo modo de hacer economía, o sea el establecimiento de una racionalidad económica especial, distinta, alternativa, que da lugar: a nuevas formas basadas en la solidaridad y el trabajo; a nuevas formas de distribución que articulan relaciones de intercambio justas con relaciones de comensalidad, cooperación, reciprocidad y mutualismo; a nuevas formas de consumo que integran las necesidades comunitarias y sociales a una matriz de necesidades fundamentales para el desarrollo integral del hombre y la sociedad; y a un nuevo modo de acumulación, centrado en los conocimientos, las capacidades de trabajo, la creatividad social, la vida comunitaria y los valores humanos, capaz de asegurar un desarrollo sustentable social y ambientalmente" (Razeto, 2002:5)

La Cooperativa propone un concepto de desarrollo humano, que se concibe como integral, complejo y solo alcanzable en plenitud por medio de: asociatividad, cooperación, puesta en común de recursos, esfuerzos y gestión cooperada y democrática, que supera el mero tecnicismo del crecimiento o el enriquecimiento 
individual y permite la apropiación colectiva de los beneficios empresariales extendidos a los sociales y a las responsabilidades de sostenibilidad generacional.

\section{Los modelos - referentes internacionales}

La práctica cooperativa en la modalidad de ahorro y crédito ha tenido en Colombia la influencia de sistemas o movimientos de gran importancia en el ámbito mundial. Entre ellos los que destacan son: El gran movimiento de Cajas Populares Desjardins de la Provincia de Québec (Canadá) de principios del siglo XX y que continúa en su vigencia como referente obligado; las Uniones de Crédito Norteamericanas (Credit Union) y las Cajas Raiffeisen de Alemania, entre varios. Estos movimientos fueron emulados en determinadas modalidades, métodos y formas de operación en Cooperativas que se crearon en Colombia y de manera especial, a partir del trabajo que realizó la Unión Cooperativa Nacional de Ahorro y Crédito - UCONAL - desde el año 1.959, gracias a la cual se le dio gran impulso a esta forma especializada de Cooperativa y ubicó al subsector de Ahorro y Crédito en una posición de liderazgo e importancia relevante dentro del cooperativismo colombiano.

Se observa simultáneamente que, las otras organizaciones de integración, en esta u otras épocas, sin demeritar el esfuerzo hecho por cada una, no tuvieron o han tenido la misma visión, pedagogía, acogida, musculo operativo o empuje. Por ello, otros renglones de desarrollo en donde el cooperativismo ha aportado significativos avances en otras latitudes, en Colombia no se presentan como experiencia de impacto.

En su devenir, la práctica del ahorro y el crédito en las organizaciones cooperativas tuvo grandes y notorias realizaciones, como también algunas desviaciones doctrinarias y métodos o procedimientos que menoscabaron su autenticidad y su solidez social y empresarial.

Las cifras de crecimiento en número de organizaciones, de asociados vinculados, de operaciones e incidencia en los rubros de ahorro y de crédito popular se muestran muy significativas para los años 60's en los cuales ya existe Uconal, y se crea Coopdesarrollo como entidades complementarias en servicios a los trabajadores organizados, sean en sus propias cooperativas promovidas o a través de otras tales como sindicatos y juntas de vecinos, crean un sistema de red nacional de vinculados a través de afiliación a estas dos organizaciones de segundo grado.

Los años 70's son particularmente florecientes; la sistemática formación de cuadros de dirigencia y la implementación de métodos y protocolos de operación para aseguramiento de riesgos y para el manejo del ahorro y el crédito otorgado, aun siendo con sus propios asociados; rinde sus frutos. Temas como el manejo del efectivo, márgenes de reserva, estudios de crédito bajo métodos de cálculo de riesgos de deudor y de empresa responsable de descuentos por nómina, procedimientos de verificación y disciplinas de verificación de los destinos finales de crédito, fueron algunos de los protocolos que la red respetaba y acataba, so pena de ser sancionado o reconvenido al tenor de estatutos y reglamentos previamente acordados. 
El análisis del entorno y de la estructura de la organización sirve como herramienta para definir las estrategias de desarrollo. Este es un proceso en el que intervienen distintas personas, organizaciones y entidades; contribuyendo a reflexionar en decisiones estratégicas a lo largo de la existencia de la cooperativa. Se observan diversos métodos tales como: La reingeniería, la planeación estratégica, la elaboración de planes de desarrollo o de calidad total, entre los más destacados, que son seguidos por las cooperativas para plantearse su proyección y desarrollos futuros.

Los Modelos retomados por las cooperativas, se conciben a partir de una alianza estratégica entre referente y emulador, que trae beneficios en la medida que se realicen intercambios de una manera transparente y con equidad, para las partes que intervienen en el acto.

Realizar alianzas con otras cooperativas que tengan experiencias significativas o que hayan obtenido trascendencia reconocida en el sector, para luego transformar, adaptar y aplicar de acuerdo a las necesidades particulares, es una constante observada entre las cooperativas participantes en la investigación.

Es así como dichos intercambios y acuerdos permiten extender buenas prácticas y establecer parámetros de control de riesgos, cuando el proceso de integración es fuerte y técnicamente orientado.

No obstante, las circunstancias de prosperidad y éxito mostrados en crecimientos o por acogida tanto en comunidades y esferas de gobiernos locales y regionales, relaja la disciplina y se pasa a un sistema de integración débil, muy centralizado y político, que se caracteriza por insuficiente o inadecuado autocontrol y a la vez, afectado por escasa o ineficaz supervisión gubernamental.

Las situaciones de riesgo madurados y crisis no se hacen esperar, dando lugar a intervenciones de autoridades nacionales, que derivan en procesos de ajuste, transformación, liquidación, escisión, fusión o incorporación de cooperativas, con emisión de la norma -Ley 454 de 1998- que fuera una emitida por urgencia y para justificar jurídicamente la intervención de sus organizaciones más incidentes por cobertura, aquellas de grado superior, entre las cuales se cuentan los tres bancos cooperativos que habían sido creados en virtud de la norma que, en su momento brindó al movimiento esta posibilidad, la Ley 079 de 1.988 .

Pero igualmente, hacen tendencia por simulación de modas o malas prácticas derivadas de una integración con politización de las acciones dirigenciales y gerenciales. Este último modus operandi promueve la figuración y el querer ser lo que no se es, por ejemplo, aplicar como bancos comerciales en operaciones de alto riesgo; ampliar bases de asociados sin previo estudio de sus reales incidencias, adelantar operación de nuevos productos con serias falencias en soportes técnicos, desconocimiento del mercado y de sus circunstancias cambiantes; todo por la aspiración de figuración y resonancia mediática.

La serie de cuadros que se presentan a continuación, contienen una síntesis de los referentes conceptuales encontrados en el recorrido histórico del estudio, para los periodos de: finales de siglo XIX, siglo XX y el siglo XXI en los 13 primeros años.

Ellos permiten una rápida mirada a las teorías o propuestas más significativas tomadas en cuenta por los promotores de las organizaciones cooperativas al momento de creación o en desarrollo de acciones decisivas para las organizaciones 
$\mathrm{y}$, también para aquellos actores que hoy, siguen reconociendo igualmente esos mismos referentes, quienes expresan su valor como incidentes para decisiones y comparaciones en el subsector de ahorro y crédito o financiero cooperativo.

Las estructuras e incluso los significados, como veremos más adelante, se ha visto modificados en su etimología y también en las prácticas emuladas, en consecuencia. Algunas de ellas han sido factores de una incidencia representativa en lo que hace a su naturaleza inicial, mostrando algunas tendencias impactantes.

Los cuadros, que se presentan a continuación son una construcción propia, que desde una perspectiva histórica y a manera de síntesis ofrecen un abordaje de cinco referentes conceptuales importantes: 1 Siglo XIX Primera mitad. 2 Siglo XIX segunda Mitad -Expansión. 3 Antecedentes Referentes conceptuales 3 Siglo XX Primera mitad. 4 Siglo XX Segunda mitad y 5. Siglo XXI Primeros 15 años en cada uno de estos cuadros se trabajan 4aspectos centrales a saber: entorno general, mundo cooperativo, mapa de experiencias y los referentes conceptuales según la época en que acontecieron los hechos. 
Tabla. 1. Referentes conceptuales 1. Siglo XIX Primera mitad.

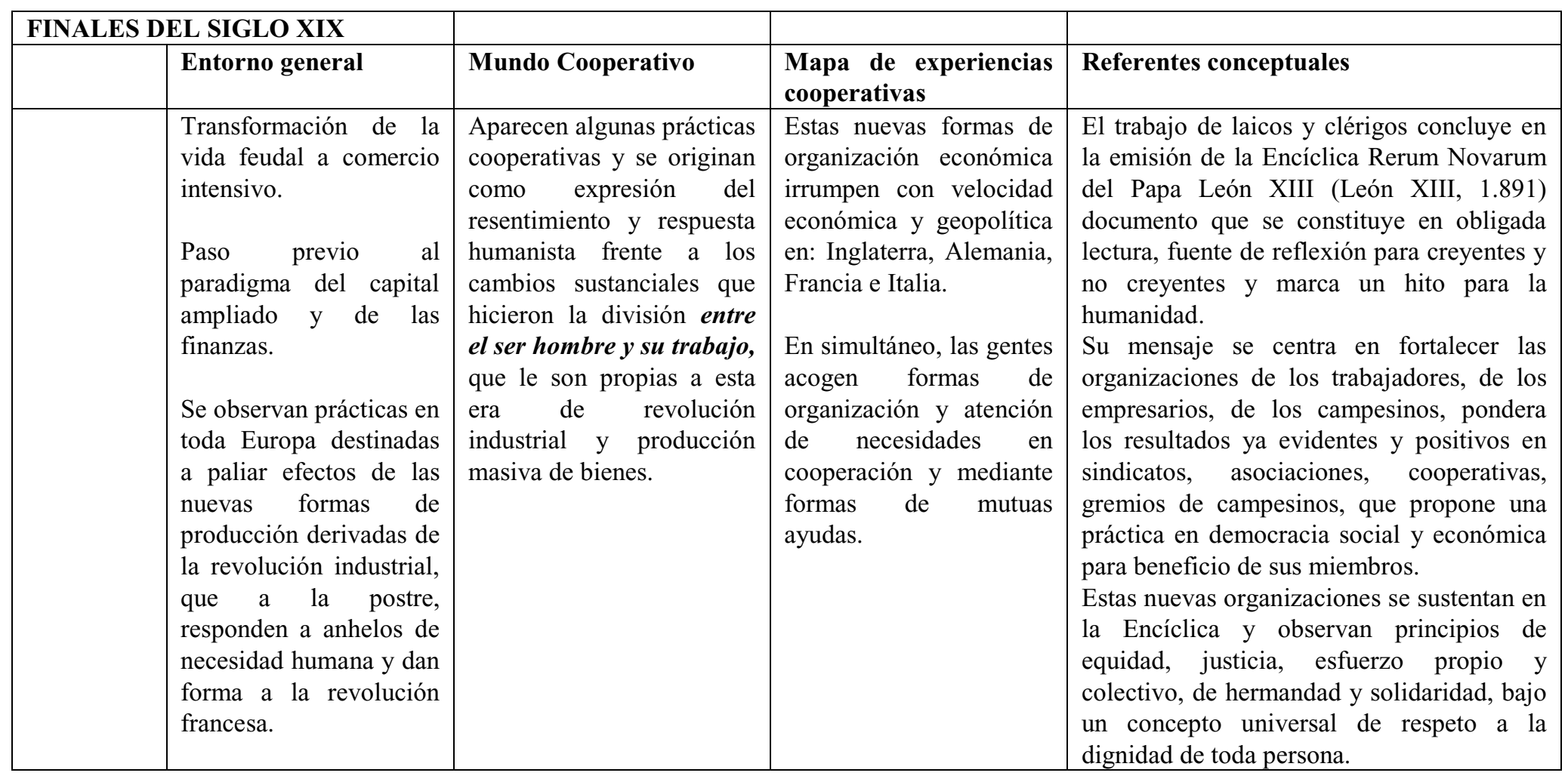


Tabla. 2. Referentes conceptuales 2. Siglo XIX segunda Mitad -Expansión-.

\begin{tabular}{|c|c|c|c|}
\hline \multicolumn{4}{|l|}{ FINALES DEL SIGLO XIX } \\
\hline Entorno general & Mundo Cooperativo & Mapa de cooperativas & Referentes conceptuales \\
\hline $\begin{array}{l}\text { Todas las experiencias } \\
\text { de capitales en sus } \\
\text { prácticas } \\
\text { organizacionales se } \\
\text { trasladan de los núcleos } \\
\text { de poder a sus zonas de } \\
\text { influencia. } \\
\text { Los movimientos } \\
\text { sociales a su vez, se } \\
\text { extienden con gran } \\
\text { rapidez auspiciados por } \\
\text { instituciones y } \\
\text { personas, se inspiran en } \\
\text { fuentes de un nuevo } \\
\text { humanismo. }\end{array}$ & $\begin{array}{l}\text { Presencia sustantiva de la } \\
\text { Iglesia Católica e iglesias } \\
\text { cristianas protestantes } \\
\text { posteriores a la reforma. } \\
\text { Sus laicos se dedican a la tarea } \\
\text { de organizar a los trabajadores } \\
\text { de fábricas nacientes, a } \\
\text { aprendices de talleres, a } \\
\text { miembros de las comunidades } \\
\text { rurales y a los vecinos de las } \\
\text { barriadas en las ciudades. } \\
\text { La corriente del socialismo } \\
\text { científico, radical y opositor a la } \\
\text { naciente ola capitalista, también } \\
\text { ven en esta forma de } \\
\text { organización una muy oportuna } \\
\text { para promover sus tesis de } \\
\text { reivindicaciones y nueva } \\
\text { sociedad. }\end{array}$ & $\begin{array}{l}\text { Se extiende desde Europa } \\
\text { y sus colonias de Canadá y } \\
\text { Estados Unidos de una } \\
\text { parte y desde Sur Asia de } \\
\text { otra. } \\
\text { La práctica cooperativa } \\
\text { llega a Canadá y desde ésta } \\
\text { a los Estados Unidos y a } \\
\text { América Latina en el } \\
\text { mundo de Occidente. } \\
\text { En Europa del Este a } \\
\text { medio siglo se observan en } \\
\text { Rusia y la zona de medio } \\
\text { oriente. }\end{array}$ & $\begin{array}{l}\text { El mapa de tendencias en prácticas } \\
\text { cooperativas para ésta época es el } \\
\text { siguiente: } \\
\text { - Consumo: Inglaterra, Francia, } \\
\text { Italia, Suecia, Rusia y otras Europa } \\
\text { Este. } \\
\text { - Trabajo y Producción en sus } \\
\text { diversas actividades, así: } \\
\text { a) Industrial- artesanal: Francia, } \\
\text { Inglaterra } \\
\text { b) Trabajo y producción campesina y } \\
\text { rural: Francia, Alemania, Canadá, } \\
\text { Estados } \\
\text { c) Ahorro y Crédito: Prestamos a } \\
\text { artesanos y campesinos: Canadá } \\
\text { d) Ahorro y Crédito ampliado a todos } \\
\text { los actores económicos: Alemania, } \\
\text { Francia, Canadá. }\end{array}$ \\
\hline
\end{tabular}


Tabla. 3. Antecedentes Referentes conceptuales 3. Siglo XX Primera mitad.

\begin{tabular}{|c|c|c|c|c|}
\hline \multicolumn{2}{|c|}{ SIGLO XX } & \multirow[b]{2}{*}{ Mundo Cooperativo } & \multirow[b]{2}{*}{ Mapa cooperativo } & \\
\hline & Entorno general & & & Referentes conceptuales \\
\hline & $\begin{array}{l}\text { Este Siglo muestra } \\
\text { dos etapas muy } \\
\text { definidas por } \\
\text { preguerra } \\
\text { posguerras } \\
\text { mundiales. } \\
\text { Las colonias se } \\
\text { independizan de los } \\
\text { imperios europeos y } \\
\text { se da un desarrollo } \\
\text { acelerado de la } \\
\text { investigación } \\
\text { aplicada. de de } \\
\text { La segunda mitad con } \\
\text { la guerra fría y el } \\
\text { gran desarrollo del } \\
\text { capitalismo en todo el } \\
\text { planeta. a da } \\
\text { La caída del muro de } \\
\text { Berlín dibuja la } \\
\text { nueva era del modelo } \\
\text { neoliberal, como } \\
\text { único dominante, que }\end{array}$ & $\begin{array}{l}\text { Se identifica por discusión } \\
\text { de conceptos, teorías e } \\
\text { ideologías. } \\
\text { Discusión entre socialistas } \\
\text { utópicos, capitalistas a } \\
\text { ultranza y moderados, de } \\
\text { una parte, frente a socialistas } \\
\text { científicos y su propuesta de } \\
\text { estado colectivo } \\
\text { comunista, de otra. } \\
\text { Ideologías que, en sus } \\
\text { discursos y práctica } \\
\text { económica llevan al mundo } \\
\text { a dos guerras mundiales y a } \\
\text { una división de norte sur, } \\
\text { este y oeste. } \\
\text { Se posiciona el concepto de } \\
\text { sector privado y sector } \\
\text { público; se trabaja sobre los } \\
\text { supuestos de paliar los } \\
\text { resultados indeseados de la } \\
\text { libertad de mercados - que } \\
\text { sigue siendo mirado como la }\end{array}$ & $\begin{array}{l}\text { América Latina aparece en el } \\
\text { contexto internacional cooperativo, } \\
\text { promovido por estrategias } \\
\text { educativas que se estructuran desde } \\
\text { Canadá y posteriormente desde } \\
\text { Estados Unidos. } \\
\text { A partir de la noción del Estado } \\
\text { Nación. } \\
\text { La idea toma mayor fuerza por la } \\
\text { debilidad estructural de los países } \\
\text { latinoamericanos y antiguos } \\
\text { protectorados; la estrategia es } \\
\text { proveer de recursos a las gentes que } \\
\text { no los tienen, con manejo de } \\
\text { créditos pequeños- hoy conocido } \\
\text { como microfinanzas - y de ahí su } \\
\text { inclinación a la conformación y } \\
\text { fortalecimiento de las cooperativas } \\
\text { de ahorro y crédito a nivel de las } \\
\text { localidades pequeñas - rurales, } \\
\text { entre grupos de trabajadores de } \\
\text { unidades fabriles que en su mayoría } \\
\text { están organizados en sindicatos. }\end{array}$ & $\begin{array}{l}\text { Todos, menos los capitalistas puros, } \\
\text { ven la forma cooperativa como } \\
\text { posible y positiva al desarrollo } \\
\text { humano. } \\
\text { Para los capitalistas puros la } \\
\text { cooperación entre los pobres es solo } \\
\text { un mecanismo de retención de brotes } \\
\text { indeseados. } \\
\text { Se promueve la percepción de que las } \\
\text { cooperativas "son de pobres y para } \\
\text { los más pobres" y una ideal estrategia } \\
\text { de organizar y manipular grupos } \\
\text { disidentes, marginales o marginados. } \\
\text { Las cooperativas se convierten en } \\
\text { herramienta para canalizar las } \\
\text { acciones de los estados, y en } \\
\text { operadores de políticas públicas para } \\
\text { redistribuir la riqueza marginal que se } \\
\text { pierde en las dinámicas de los } \\
\text { mercados cada vez más ampliados. } \\
\text { Es una forma que conserva lo antiguo }\end{array}$ \\
\hline
\end{tabular}




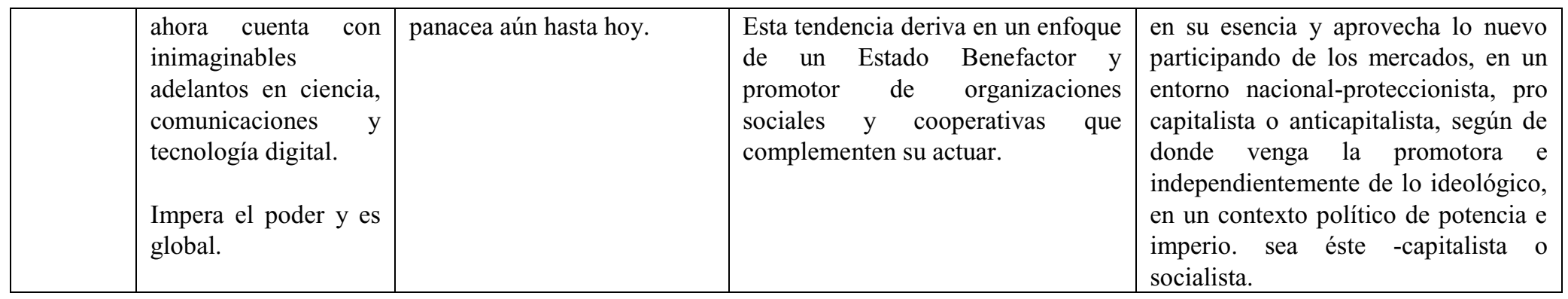


Tabla. 4. Referentes conceptuales 4. Siglo XX Segunda mitad.

\begin{tabular}{|c|c|c|c|c|}
\hline \multicolumn{5}{|c|}{ SIGLO XX } \\
\hline & $\begin{array}{l}\text { Entorno } \\
\text { general }\end{array}$ & Mundo Cooperativo & $\begin{array}{l}\text { Mapa } \\
\text { cooperativo }\end{array}$ & Referentes conceptuales \\
\hline $\begin{array}{l}\text { Segunda } \\
\text { Mitad }\end{array}$ & $\begin{array}{l}\text { La segunda } \\
\text { mitad del } \\
\text { siglo, marcada } \\
\text { por la } 2^{\mathrm{a}} \text { post } \\
\text { guerra, la } \\
\text { caída del } \\
\text { Imperio } \\
\text { Alemán y los } \\
\text { acuerdos entre } \\
\text { los actores } \\
\text { aliados y } \\
\text { ganadores. } \\
\text { Se definen } \\
\text { mecanismos } \\
\text { internacionale } \\
\text { s que } \\
\text { potenciarán al } \\
\text { capitalismo } \\
\text { con gran } \\
\text { dinamismo y } \\
\text { aparecen } \\
\text { teóricos de la } \\
\text { administración }\end{array}$ & $\begin{array}{l}\text { Surgen organismos } \\
\text { internacionales para la } \\
\text { diplomacia, } \\
\text { representación } \\
\text { negociación de los } \\
\text { Estados } \quad \text { Nación. } \\
\text { En réplica aparecen } \\
\text { aquellos organizados por } \\
\text { movimientos sindicales, } \\
\text { sociales y cooperativos. } \\
\text { OIT, ACI con alcance } \\
\text { mundial para lo laboral y } \\
\text { cooperativo en general. } \\
\text { Además WOCCU y } \\
\text { COLAC especializados } \\
\text { de cooperativas de } \\
\text { Ahorro y Crédito, con } \\
\text { alcances mundial y } \\
\text { latinoamericano; con } \\
\text { homólogos en los otros } \\
\text { continentes. } \\
\text { Los enfoques son } \\
\text { diversos, respetan los }\end{array}$ & 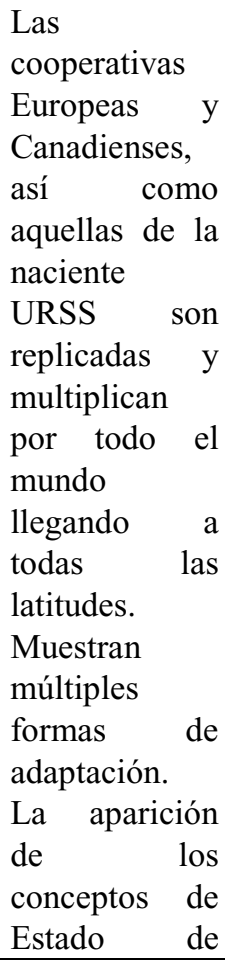 & $\begin{array}{l}\text { Dos ideólogos y autores son citados como especialmente influyentes, } \\
\text { en varios documentos y por los autores de El Cooperativismo Mundial } \\
\text { (Pineda et all, 1998): P.C Plockboy: Holandés (1659) propone respetar } \\
\text { la propiedad privada, organizar lo económico y social por grupos } \\
\text { homogéneos de artes u oficios, agricultores, pastores, artesanos, } \\
\text { marinos, maestros de artes o de las ciencias. } \\
\text { Jhon Bellers, Inglés (1654- 1725): complementa la propuesta de } \\
\text { Plockboy y sugiere colonias de trabajo, dando primacía a éste por } \\
\text { encima del dinero, porque es el trabajo el factor definitorio y generador } \\
\text { de riqueza. Estos dos autores marcan tendencia. La cooperativa va a } \\
\text { considerar como una de sus funciones económicas: eliminar los } \\
\text { intermediarios y dar viabilidad a una forma de democracia económica } \\
\text { y a la vez social de participación de todos los miembros. } \\
\text { Estas ideas calan hondo en los seguidores, se ponen en práctica y son } \\
\text { base de experiencia sistematizada que con el tiempo se plasma en los } \\
\text { principios cooperativos hoy conocidos. A partir de estas enseñanzas y } \\
\text { tendencia incidente, no existe una vertiente única. } \\
\text { Otros autores representativos y que han sido inspiración de los } \\
\text { cooperadores, tales como Robert Owen, Charles Fourier, William } \\
\text { King, Felipe Buchez, Louis Blanc, Friedrich Wilhelm Raiffeisen, Franz } \\
\text { Hermman Schulze-Delitzsch, entre los más nombrados, son } \\
\text { reconocidos como constructores de doctrina y teoría con sus prácticas } \\
\text { iniciales. Seguidos por los más cercanos al siglo XX como Luiggi }\end{array}$ \\
\hline
\end{tabular}




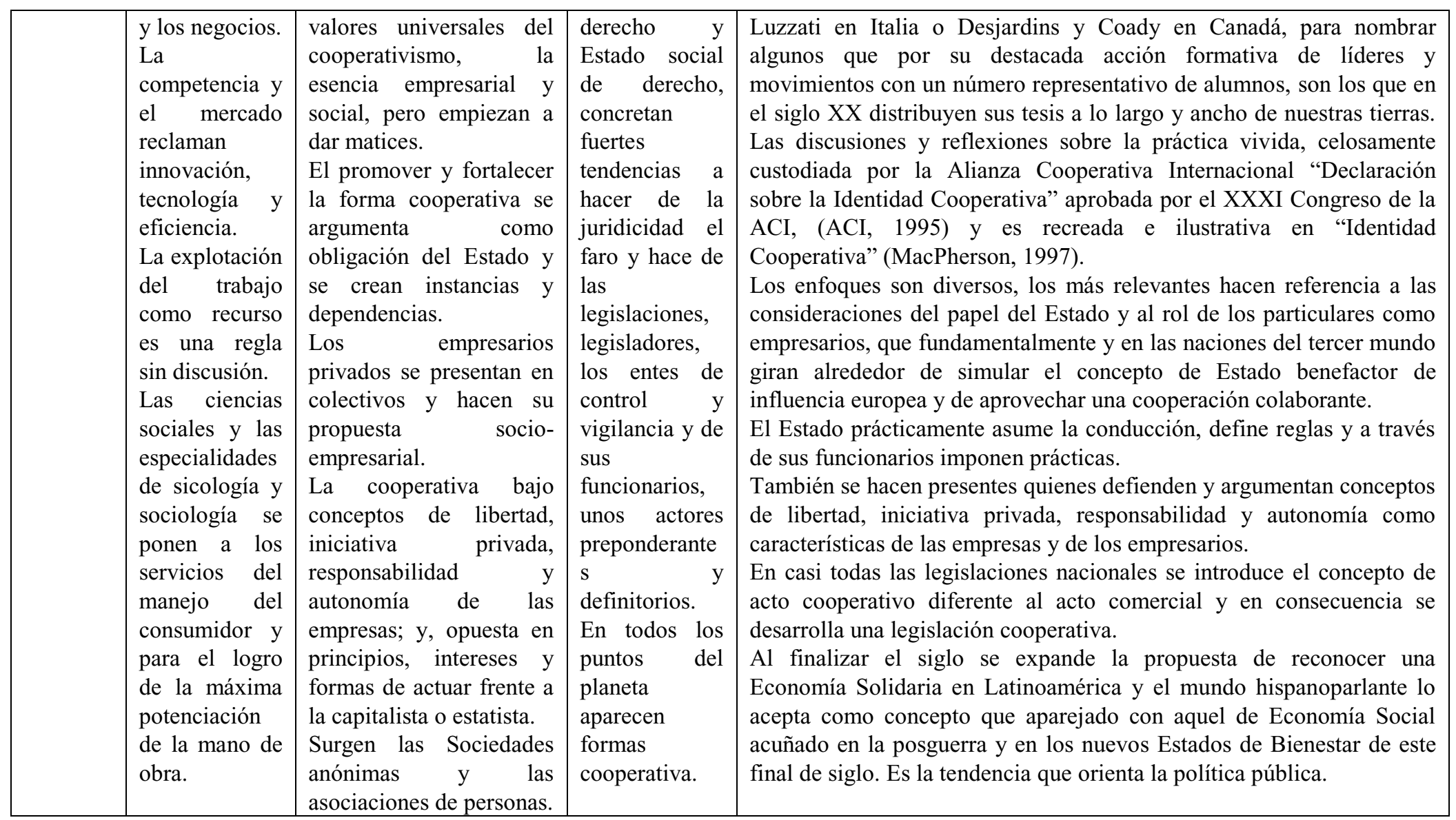


Tabla. 5. Referentes conceptuales 5. Siglo XXI Primeros 15 años.

\begin{tabular}{|c|c|c|c|c|}
\hline \multicolumn{5}{|c|}{ SIGLO XXI } \\
\hline \multirow[b]{2}{*}{$\begin{array}{l}\text { Primeros } \\
15 \text { años }\end{array}$} & Entorno general & Mundo Cooperativo & Mapa cooperativo & Referentes conceptuales \\
\hline & $\begin{array}{l}\text { El siglo XXI inicia con una } \\
\text { humanidad preocupada, más } \\
\text { no ocupada, por tres de los } \\
\text { más grandes problemas que } \\
\text { amenazan a la humanidad, } \\
\text { todos consecuencia del error } \\
\text { de creer que el modelo del } \\
\text { beneficio máximo y la mano } \\
\text { invisible del mercado } \\
\text { subsanan todos sus efectos y } \\
\text { consecuencias, indeseadas e } \\
\text { imposibles de prever- dicen } \\
\text { algunos- y necesarias- dicen } \\
\text { los más recalcitrantes. } \\
\text { Dichos problemas son: } \\
\text { - Extrema } \\
\text { pobreza de millones } \\
\text { de seres humanos } \\
\text { con hambrunas y }\end{array}$ & $\begin{array}{l}\text { Sus estructuras } \\
\text { empresariales se ven } \\
\text { permeadas, muchas veces } \\
\text { por imposiciones } \\
\text { gubernamentales, con las } \\
\text { nuevas tendencias de } \\
\text { Responsabilidad } \\
\text { organizacional y asumen } \\
\text { programas en ese sentido. }\end{array}$ & $\begin{array}{l}\text { Los actores más } \\
\text { destacados y dinámicos en } \\
\text { ésta primera década son: } \\
\text { Japón, Sur Asia y } \\
\text { Países de la Unión Inglesa } \\
\text { U.K.: Australia, Nueva } \\
\text { Zelanda, Canadá. } \\
\text { En casi todos los países de } \\
\text { América Latina los actores } \\
\text { cooperativos se ven } \\
\text { golpeados por las } \\
\text { reiteradas crisis. } \\
\text { Las cooperativas siendo } \\
\text { las primeras afectadas se } \\
\text { ven denigradas y pierden } \\
\text { confianza; se da amplia } \\
\text { promoción negativa desde }\end{array}$ & 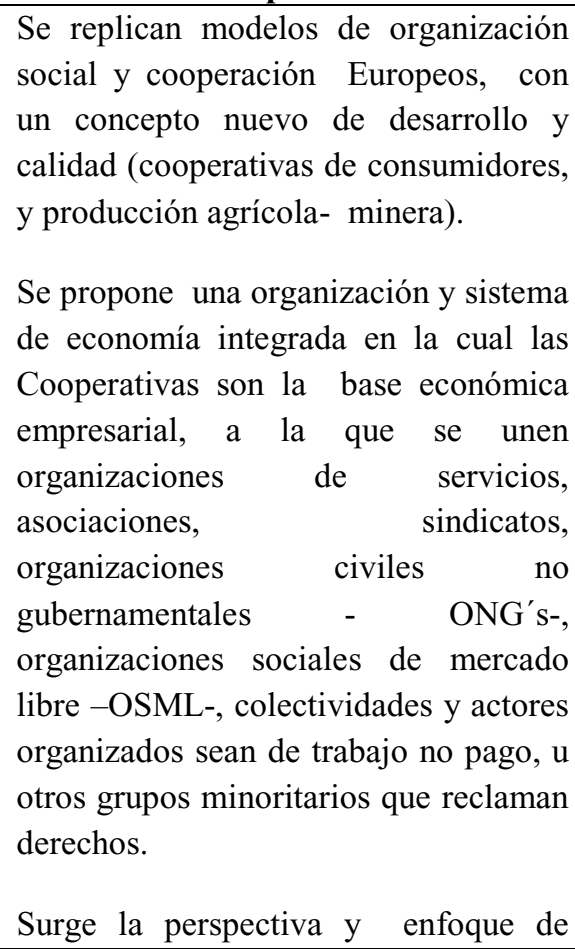 \\
\hline
\end{tabular}




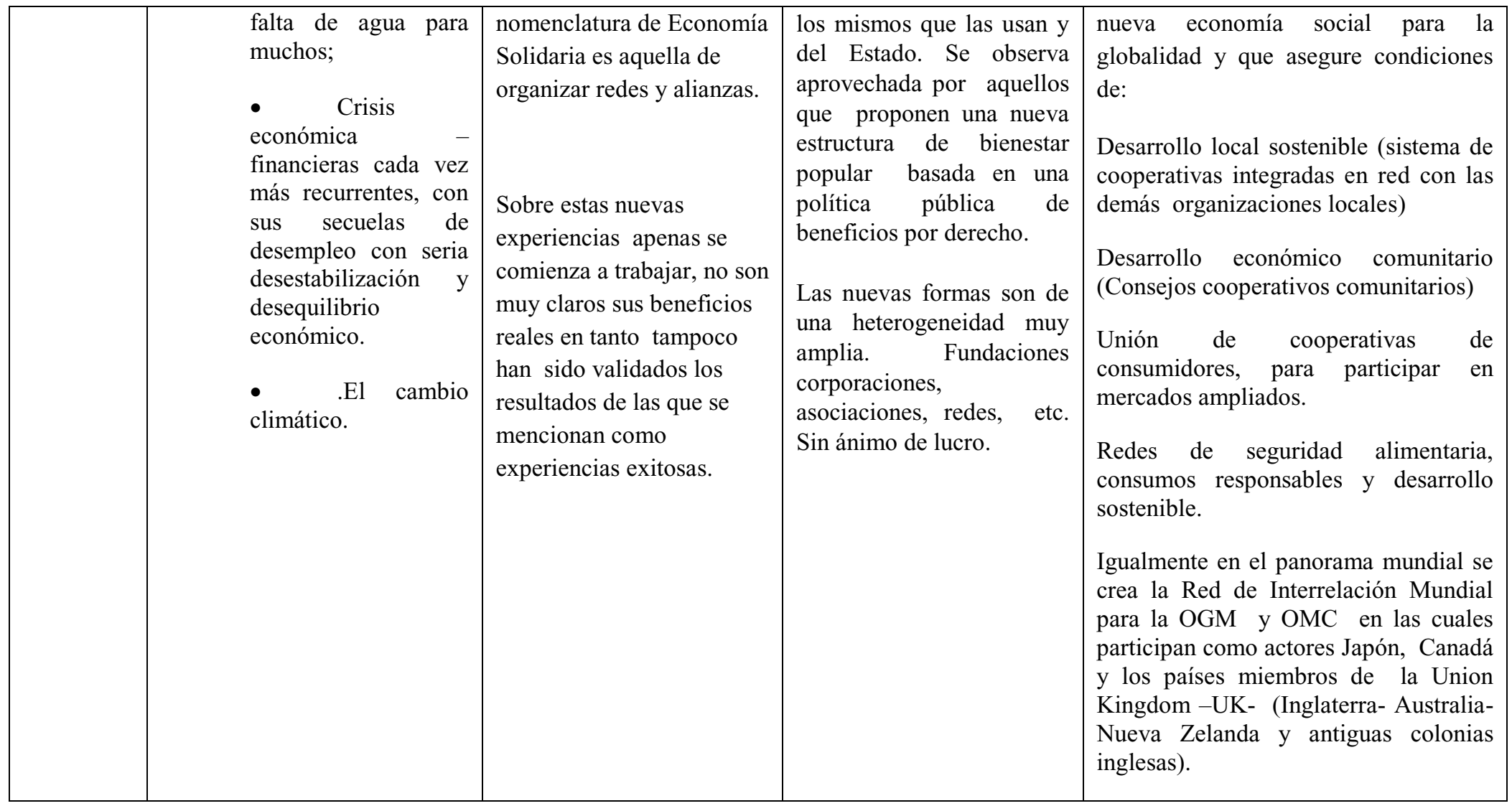

Fuente: Elaboración propia 


\section{El cómo del modelo nacional en Colombia}

Es importante resaltar en este punto del presente texto, que la búsqueda del cómo en el modelo nacional colombiano es abordada por las suscritas autoras, tomando aquellos trabajos que, habiendo sido orientados bajo la misma línea de investigación, preceden al presente, como base de datos inicial, desde la cual se plantea un avance de profundización.

Es así cómo, para refrendar la información lograda en la revisión documental e histórica de los textos y documentos estudiados, el trabajo de campo en la presente investigación, toma las actas de trabajo de campo y trabajos finales elaborados por los estudiantes de la Universidad Cooperativa de Colombia ${ }^{3}$, las que seleccionadas de la base de trabajos en plataforma, ubicado en el repositorio de trabajos de clase, permiten la escogencia de 340 que cumplen a cabalidad parámetros y protocolos en cuanto a: homogeneidad en la información, calidad en el trabajo de recolección de dicha información, validez de fuente entrevistada, y suficiencia en la información solicitada.

El primer análisis de esta muestra así seleccionada da como resultado una identificación de tipificación de modelos de cooperativas dentro de aquellas que siendo de ahorro y crédito o financieras ${ }^{4}$ muestra una diferenciación en su modelo organizacional, sin que ello signifique necesariamente que dejen de serlo.

Bajo dicha tipificación finalmente se seleccionan a: Coofinal, Beneficiar, Cooptenjo, Cooprofesionales, Cooprofesores, Coopbelen, Coomeva financiera y Confiar, como objetos de estudio - tipificado- para adelantar un nuevo trabajo de campo, como estudio de caso a profundidad y como nueva fuente de información y opinión del cómo se ha forjado el modelo colombiano, según la versión y desde sus actores entrevistados.

\subsection{Hallazgos y resultados}

Los hallazgos y resultados se sintetizan a continuación y hacen evidente las incidencias de los diversos referentes conceptuales internacionales antes mencionados y que fueron encontrados en una muy juiciosa revisión documental.

\section{Actores referentes:}

El hallazgo más evidente del presente trabajo de profundización, tratándose de las cooperativas de ahorro y crédito, -se aclara que no ocurre así o en general en otros sectores de actividad económica, cooperativa por supuesto, como puede ser en el transporte o la producción y trabajo-, todos los actores entrevistados reconocen la

3 Todos los pensum de todas las carreras, tanto profesionales como en tecnologías, ofrecidos a los estudiantes de la Universidad Cooperativa de Colombia, y matriculados entre los años 2009 y 2012 inclusive, contienen 6 asignaturas de economía social, solidaria y cooperativa. En dichos cursos se exige un trabajo final. Para el caso, dichos trabajos finales fueron insumos que aportaron a las línea de investigación sobre la temática y que para estos períodos consistió en hacer el levantamiento de existencia y situación de las cooperativas en cada territorio (18 sedes a nivel nacional), bajo una misma orientación metodológica - estudio de caso- y según técnica unificada con suministro de un solo formato y herramientas predeterminadas por las investigadoras.

4 Clasificación por diferenciación en su actividad, según la ley 454 de 1998. 
importancia y valor de haber tenido en cuenta orientaciones de los siguientes organismos internacionales:

- La Iglesia Católica, como promotor inicial y fuente filosófica desde los postulados desde su Doctrina Social de Iglesia. Se hacen presentes en los relatos nombres tales como: el Pro Marco Fidel Reyes, Francisco Mejía S.J. y muchos otros, miembros de la Compañía de Jesús -padres Jesuitas- y curas párrocos -miembros de la Iglesia Diocesana- cuyos nombres quedaron anónimos, pero que a su vez dieron abrigo en sus parroquias a las pequeñas cooperativas que se iniciaban.

- Woccu -(por sus siglas en ingles) Consejo Mundial de Cooperativas y su Secretaría de Educación, especialmente en la etapa posterior a 1990, para las experiencias de insertar el microcrédito como una oferta de servicios especifica y sistematizada, y las prácticas en red Sumared y Sugiro a nivel nacional, que hace una mirada hacia un mercado internacional.

- Entre las $\mathrm{ONG}^{6} \mathrm{~s}$ internacionales destaca Acción International, como ente asesor en la implementación de metodologías de manejo de microcréditos. Nueva modalidad de acción para llegar a lo que se conoce como estrategia de bancarización de las clases populares y vulnerables, por parte del sistema financiero reconocido como tal, en la legislación tanto nacional como internacional.

- En relación con formación de cuadros - líderes o promotores y educación para la cooperación, destaca la gran influencia de la Escuela de Antigonish, Universidad San Francisco Javier (no Jesuítica) de Canadá. Esta escuela de formación se menciona como formadora de los líderes y liderezas de primera generación al inicio del siglo XX, destaca varios y entre ellos: Rymel Serrano Uribe y su hermano, los cuatro Hermanos Niño Rodríguez y sus hermanas, Carlos Uribe Garzón, Los hermanos Espinosa y varios líderes muy destacados vinculados con organizaciones sindicales tales como UTC y CGT, la gran mayoría, aunque igualmente se mencionan vinculados a la CTC, todos ellos activos en los años 50's.

Por último y como actor internacional referente, muy reciente pero de gran significancia por la coyuntura en el momento en el que se hace obligatoria para las cooperativas la observancia de las normas que propone al sistema financiero, aparecen los modelos de Basilea. Estos aunque modelos bancarios, a partir de los efectos de crisis reiteradas, se hacen imperativos a todo actor financiero en el mercado nacional colombiano, incluidas las cooperativas a partir del año que cierra en 1.999 .

5 "El Consejo Mundial de Cooperativas de Ahorro y Crédito (WOCCU) es la asociación gremial y agencia de desarrollo para el sistema internacional de cooperativas de ahorro y crédito. WOCCU promueve el crecimiento sustentable de las cooperativas de ahorro y crédito y otras cooperativas financieras en todo el mundo a fin de facultar a las personas para que mejoren su calidad de vida a través del acceso a servicios financieros asequibles y de alta calidad. WOCCU realiza esfuerzos de defensa activa en representación del sistema global de cooperativas de ahorro y crédito ante organizaciones internacionales y trabaja con gobiernos nacionales para mejorar la legislación y la regulación. (www. woccu:2009).

6 ONG,s refiere a Organizaciones sin ánimo de lucro o con dicho ánimo pero dedicadas a actividades destinadas al servicios social, que no siendo gubernamentales, tampoco ejercen la actividad comercial de los productos o servicios que ofrecen y lo hacen generalmente a grupos u otras entidades en necesidad. 


\section{Incidencia de modelos y prácticas referentes}

La experiencia más significativa por sus repercusiones en el desarrollo del sector tiene que ver con las prácticas de Ahorro y Crédito en las Organizaciones Cooperativas; el análisis se centró en la influencia que han tenido los modelos referentes para estas organizaciones.

Los modelos y prácticas mencionados como positivos para las cooperativas, según lo expresado por los participantes en el estudio, y que se reconocen como benéficos para ser emulados y sostenidos o incluso fortalecidos son los siguientes:

- UCONAL, como experiencia gremial y organización conformada por líderes formados en la Escuela de Antigonish, que a su vez sigue el modelo de estructura operativo-funcional de las Credit Union de Cuna Mutual, Estados Unidos, como fuente del modelo original de Ahorro y Crédito de Colombia.

- Esta influencia se registra especialmente por ser fuente de sustento teórico, metodológico y de buenas prácticas de gestión, formación y capacitación para desarrollo de técnicas, competencias funcionales y en temas especializados como orientación de prácticas pertinentes y referente de lo que era prudente en desarrollo de la actividad de crédito o financiera y lo que no era dado hacer por riesgoso e inapropiado.

- Estas prácticas, son mencionadas como fundamentales, ya que permitieron el muy reconocido crecimiento e incidencia social positiva de las cooperativas, hasta los años 80 del siglo pasado.

- Como entidades complementarias u homólogas a la anterior, pero con idéntica influencia internacional, se mencionan los modelos Coopdesarrollo, Ascoop, Indesco, Esacoop y la hoy Confecoop, que igualmente emulan o siguen los rastros de Uconal, ofreciendo formación en gestión cooperativa, capacitación para desarrollo de técnicas, competencias funcionales y en temas especializados para implementación de procesos propios de cada actividad; en tanto ellas ofrecen sus servicios de manera general a todo tipo de cooperativas.

- Modelo de Fondo de Garantía para Cooperativas para prevenir y cubrir riesgos de volatilidad para beneficio y protección de los ahorradores del sistema cooperativo. Dicho modelo y fondo sugerido en los protocolos Basilea para todo el sistema financiero mundial, se concreta en Colombia para las cooperativas en la figura - FOGACOOP-.

- Modelo para desarrollo de sistemas de monitoreo y alerta temprana como es el -PERLAS- , con medición de sanidad de las estructuras de operación y balances. Es un modelo que trabajado como prueba piloto entre el Consejo Mundial de Cooperativas de Ahorro y Crédito (WOCCU) y 10 cooperativas colombianas de común acuerdo, permite gestionar un acuerdo entre $\mathrm{La}$ Superintendencia de la Economía Solidaria y la Organización Mundial de Cooperativas -WOCCU- que implementa esta herramienta a nivel de todos los actores cooperativos de ahorro y crédito o financieros cooperativos.

- $\quad$ El Grupo Cooperativo de Mondragón, España, igualmente es mencionado como referente para un intento de cooperativismo de Ahorro y Crédito que pueda impulsar proyectos de producción local. 
Por último se mencionan a las Entidades Dancoop, Dansocial y Supersolidaria, del Gobierno Nacional, como receptoras obligadas de las políticas internacionales de control, en este caso como lo es la normatividad de Basilea. Estos agentes de Estado, son entes responsables de la normatividad general del sector cooperativo, quienes junto con algunas Universidades, han permitido avances y dedican su actuar a temas normativos, de control y supervisión fiscal, contable y de gestión.

\section{Modelos desde la propuesta nacional colombiana:}

Desde la tipificación que permite la selección de los casos de estudio a profundidad para el presente trabajo se puede inferir el cómo el modelo colombiano se va conformando.

- Se destaca como modelo "sui generis" el de los fondos sociales acumulables que hace Coomeva, hoy convertida en varias empresas, en su mayoría sociedades anónimas que han absorbido las diversas actividades de la original Coomeva y que al momento de la entrevista solo actúa como tal, Coomeva Financiera.

La cooperativa siendo originalmente multiactiva, se reestructura a especializada de ahorro y crédito, pasa posteriormente a cooperativa financiera y finalmente, traslada sus activos a un banco comercial bajo figura de sociedad anónima, cuyas acciones se mencionan de propiedad de la cooperativa, nuevamente multiactivas en la que se convierte. En esta última figura la actividad financiera ha sido instrumento de manejo descentralizado y aislado de la gestión cooperativa y es el banco el que maneja los fondos sociales como un activo de riesgo.

Este es un modelo, que muestra mucha influencia en sus homólogas para los años 2009 y siguientes, es un referente entre las cooperativas de gran tamaño, ejemplo Juriscoop y otras similares, que bajo control de la Superintendencia Financiera, se ven alentadas por este ente de control que ve en la conversión de estas a sociedades anónimas, la simplificación de su acción fiscalizadora por homologación con los demás entes bancarios y de crédito que vigila.

De otra parte, se reconocen como experiencias especiales las de Cooptenjo y Coopbelen, que se destacan como modelos propios.

El primero tipifica como de una cooperativa localizada en región de poblaciones rurales. Con su gestión descentralizada de servicios en oficinas ubicadas en pequeñas poblaciones de Cundinamarca.

El segundo caso, destaca como modelo de cooperativa de barrio con sentido servicio localizado en una zona y perfil urbano popular.

Estas tres cooperativas forman un grupo de cooperativas que siendo originalmente de tipo cerrado, o sea de empresa, abren sus puertas a todo tipo de personas y se amplían tanto en números de oficinas al público y en consecuencia en asociados y finalmente terminan siendo actores de mercado.

- Cooprofesionales y Cooprofesores son unas cooperativas tipificadas como modelo de la nueva generación. Son cooperativas cuya vida activa es relativamente reciente, o si alguna presenta una fecha de creación antigua, 
estuvo inactiva y vuelve a reactivarse para los años finales de 1980 y su actividad fuerte es en los años 90's y 2000.

Como se puede observar es variada la referencia de utilización de los modelos internacionales. Quizás el rasgo común está dado por que cada cooperativa ha utilizado el modelo que más se ajusta a su propia realidad y procesos, con las adaptaciones del caso; es decir, ningún modelo se ha seguido ciegamente, sino que obedece a las necesidades de desarrollo de cada organización e incluso a sus particularidades, referidas siempre a las circunstancias y a las relaciones con las regiones.

\section{Conclusiones}

A partir de la interpretación, análisis y valoración de los disímiles estudios realizados sobre el cooperativismo, desde sus orígenes, hasta la actualidad y de la identificación de sus fundamentos teóricos y metodológicos, presentes en la identidad cooperativa; desde la Globalización Neoliberal sus tendencias e impacto sobre el cooperativismo y los retos que este enfrenta; además de su confrontación con los estudios de caso tipificado abordados en el presente trabajo se pueden extractar las siguientes conclusiones:

EL rasgo importante para destacar es que las cooperativas no han tenido como parámetro el mismo modelo siempre, sino que según el momento histórico vivido les ha llevado a producir transformaciones, que traen consigo cambios en el modelo utilizado.

Es en la práctica de adaptar los modelos, los métodos y las técnicas a las particularidades y condiciones regionales, culturales e incluso políticas que presionan su entorno y se ven abocadas a definir su identidad, han evolucionado y van definiendo el ser de las cooperativas en Colombia.

Las experiencias y casos tipificados estudiados, permiten concluir que siendo consustancial en las cooperativas con identidad, independientemente del modelo funcional que hayan asumido como propio, ellas se constituyen en formas reales y muy prácticas para contribuir a ser una concreta alternativa a la Globalización Neoliberal en Latinoamérica, si y solo si, se toman en cuenta fundamentos de la identidad cooperativa tales como: Realización real de la unión de fuerzas económicas y Funcionalidad como economías colectivas.

La dimensión internacional de competencia y concentración, exige y presenta una oportunidad única a las cooperativas. Una cooperativa se convierte en experta en generar espacios donde cada uno de sus múltiples asociados (partícipes) preserva la genuina democracia cooperativa

La necesidad de trabajar con creatividad, autonomía, y con activa participación en un proceso continuo de aprendizaje y altamente comprometido con su medio social, es el ideal para una forma de trabajo cooperativo

1. El desarrollo de estrategias organizacionales para encauzar la participación.

2. Trabajo en equipo.

3. Procesos de formación colectivo. 
4. La cooperación entre las diferentes cooperativas tanto locales, regionales y nacionales.

5. Alianzas estratégicas.

6. Definiciones doctrinales de conjunto

Todas las cooperativas sujetas a estudio y señaladas como cooperativas con identidad evidente, vienen cumpliendo un papel protagónico en los manejos y temas mencionados.

Parece ser correcto inferir que lo que hace la eficacia de una cooperativa es la fidelidad a tener como referentes de decisión sus principios y ejemplos de buenas prácticas, más que emular un modelo en específico.

De igual manera se puede concluir que las acciones y prácticas prioritarias de las organizaciones cooperativas de ahorro y crédito se orientan a: incentivar el desarrollo de sus asociados, incidir en las comunidades donde actúan y a propender por un sistema sólido económico y organizativo que se presenta a la sociedad colombiana con una agenda de participación activa, aunque esta aparece marginal en la economía nacional.

En referencia a establecer una comparación entre los modelos nacionales influyentes en el cooperativismo de Colombia y las prácticas de ahorro y crédito de las organizaciones cooperativas colombianas, se pudo identificar; semejanzas y diferencias con incidencias con lo doctrinal, social, organizacional, empresarial y del entorno.

Los factores críticos observados y que han tenido efectos devastadores unos, positivos otros son esencialmente los siguientes: el reconocimiento de la identidad de las cooperativas y la conciencia de su propia naturaleza. A partir de ello, toda cooperativa que tenga claros sus derroteros, ha desarrollado estrategias propias y acordes con el contexto de las comunidades donde se hacen presentes.

Cada uno de los estudios de caso permiten evidenciar el desarrollo positivo de la gestión en general y de beneficio social que se materializa en brindar oportunidades de mejora en la calidad de vida de los asociados, sus familias y del entorno en donde actúan, aportando a la construcción de un proyecto nacional.

\section{Referencias bibliográficas}

ACI. Congreso (1980) Las cooperativas en el año 2000. Moscu.

Aldecoa (2009) La escencia de las cooperativas, Una apuesta por la Justicia. Puerto Rico, Texto de informe. p:25.

Arango, M. (2005) Manual de cooperativismo y economía solidaria. Editorial Universidad Cooperativa de Colombia. Medellín.

Colombia, Congreso de la Republica. Ley 79, Actualización de la legislación cooperativa, De las actividades financieras y de los bancos cooperativos. Bogota D.C.: Diario Oficial numero 38.648, del 10 de enero de 1989.

Colombia, Congreso de la Republica. Decreto 1111, Por el cual se reglamenta el capitulo XI de la Ley 79 de 1988 y se dictan normas para el ejercicio de la actividad financiera por parte de las entidades cooperativas. Bogotá D.C.: 1989.

Colombia, Congreso de la Republica. Ley 454, Marco conceptual que regula la economía solidaria. Bogota D.C.: Diario Oficial numero 43.357, de 6 de agosto de 1998. 
Colombia, Congreso de la Republica. Ley 795, Disposiciones que modifican el estatuto orgánico del sistema financiero. Bogota D.C.: Diario Oficial numero 45.064 de 15 de enero de 2003.

Coopetrol. Cooimpresos, $1^{\text {a }}$ Ed. 280 p.

Jaramillo, F., Serrano, R. y Uribe, C. (2005) Conversatorio sobre la "Utopía" Cooperativa. Promoviendo la doctrina y autenticidad; Bogotá; $1^{\mathrm{a}}$ Ed. Fundequidad, $156 \mathrm{p}$.

Mansilla, M. A. (2002) Por una empresa de democracia económica, Corfincora 40 años, Graficoop, Bogotá.

Müller de Ceballos, I. (1992) La Lucha por la Cultura II. Universidad Pedagógica Nacional CIUP Bogotá.

Padilla, M. R. y Atehortúa, A. L. (2005) Crisis del Cooperativismo financiero en Colombia, 1996-1998; Bogotá; Universidad Pedagógica Nacional, Colciencias, $1^{\mathrm{a}}$ ed. $151 \mathrm{P}$.

Pardo, L. P.; Serrano, R. y Jaramillo, G. (2006) Estado del arte del sector solidario en Colombia. Universidad Cooperativa de Colombia. Medellín.

Razeto, L. (2002). Ponencia presentada en el II Foro Social Mundial de Porto Alegre, en el Seminario sobre la Economía de Solidaridad. En http://www.economiasolidaria.net. Acceso: 12/07/2015.

Rosselló, P. (1974) La teoría de las corrientes educativas, Promoción cultural Barcelona, España.

Seguí, A. (2012) Cajas de ahorros: un modelo de compromiso con la sociedad. REVESCO. Revista de Estudios Cooperativos, $\mathrm{N}^{\mathrm{o}}$ 107, pp. p.155-185. DOI: 10.5209/rev_REVE.2012.v107.38744.

Uribe, C. (1998) Crisis ideológica del Cooperativismo a la luz del pensamiento de Alexander Fraser Lailaw; Bogotá: Ediciones Guadalupe, Fondo Nacional Universitario, $1^{\mathrm{a}}$ ed. 181 p. http://www.woccu.org/about. 26 de febrero de 2009. 